\title{
Sulphonylureas and hypoglycaemia
}

Hypoglycaemia is the most important and most often fatal of the adverse effects of sulphonylureas. Chlorpropamide and glibenclamide appear to cause severe hypoglycaemia more often than tolbutamide, but hypoglycaemia may occur with any sulphonylurea. Experience with newer agents is limited, and they should not be assumed to be safer in this respect than tolbutamide. A diagnosis of hypoglycaemia should be considered in patients treated with a sulphonylurea who develop disturbed cerebral function. Hospital admission is required for severe sulphonylurea induced hypoglycaemia, and successful management depends on understanding that prolonged treatment may be necessary.

The incidence of hypoglycaemia induced by sulphonylureas is probably underestimated, although few reliable data are available. A two year prospective trial recorded an incidence of symptomatic hypoglycaemia of $19 / 1000$ patients/ year $(95 \%$ confidence interval 11 to 34$),{ }^{1}$ while the incidence of hypoglycaemia requiring hospital treatment in the Swedish island of Gotland was $4 \cdot 2 / 1000$ patients/year. ${ }^{2}$ By comparison, the incidence of insulin induced hypoglycaemia requiring hospital treatment is about $100 / 1000$ patients/year. ${ }^{3.6}$ Case fatality rates among insulin treated patients admitted to hospital with hypoglycaemia are low, ${ }^{4-6}$ and there were no deaths in a prospective survey in Nottingham of 200 admissions to an accident and emergency department. ${ }^{3}$ The estimated mortality from insulin induced hypoglycaemia in Britain among patients aged under 50 is about $0 \cdot 2 / 1000$ patients/year. ${ }^{78}$ By contrast, in Sweden the mortality from glibenclamide associated hypoglycaemia calculated from reported adverse drug reactions was $0.033 / 1000$ patients/ year, ${ }^{9}$ and a Swiss survey found a case fatality rate for sulphonylurea induced hypoglycaemia of $4 \cdot 3 \%$ (95\% confidence interval 1.9 to $9 \cdot 7$ ) among 116 admissions. ${ }^{10}$

Unfortunately few published data allow direct comparison between non-insulin dependent diabetic patients treated with insulin and those treated with sulphonylureas. In one study 823 patients were randomly assigned to receive insulin, tolbutamide, or placebo ${ }^{11}:$ after five years definite or suspected hypoglycaemia requiring dose adjustment was about four times more common in the group receiving a standard dose of insulin than in the group on a fixed daily dose of tolbutamide. The trial has been widely criticised, ${ }^{12}$ and further assessment of the relative safety and efficacy of insulin and sulphonylureas must await the results of another large randomised controlled trial underway in Britain. ${ }^{13}$

The risk of sulphonylurea induced hypoglycaemia appears from the Swiss survey to be greater for some agents than for others. ${ }^{10}$ Taking the incidence of hypoglycaemia among patients treated with chlorpropamide as 100 , the standardised incidence ratios were 111 for glibenclamide (95\% CI 85 to 135), 46 for glipizide ( $95 \%$ CI 6 to 99 ), and 21 for tolbutamide (95\% CI 5 to 36$)$. The lower incidence for tolbutamide is unlikely to be caused by bias in reporting and recognising hypoglycaemia or in prescribing drugs to susceptible patients. Other evidence also suggests that the incidence is similar for chlorpropamide and glibenclamide. ${ }^{1}$ The relative risk of sulphonylurea induced hypoglycaemia increases steeply with age, ${ }^{14}$ is and other predisposing factors include reduced food intake $e^{1416}$ and intercurrent illness. ${ }^{1014}$ The effects of sulphonylureas may be potentiated by aspirin, $\beta$ blocking drugs, and preparations containing sulphonamides. ${ }^{14}{ }^{15}$

Sulphonylureas stimulate insulin secretion, which may produce hypoglycaemia in non-diabetic people. ${ }^{17}$ Higher drug concentrations, and correspondingly higher insulin secretion, might be expected from preparations with long or variable elimination half lives. Chlorpropamide has a half life of one to two days in patients with normal renal function and may cause hypoglycaemia lasting several days. ${ }^{19}$ High drug concentrations have not, however, been shown in diabetic patients with chlorpropamide induced hypoglycaemia. ${ }^{20}$ Glibenclamide probably has a plasma half life of only two to three hours ${ }^{21} 22$ but has emerged as an important cause of prolonged hypoglycaemia ${ }^{14}{ }^{1623}$; fatal cases have occurred with doses as low as $2.5 \mathrm{mg}$ a day.${ }^{14}$ Prolonged hypoglycaemia with glibenclamide may be caused by an uncharacterised metabolite, accumulation of the drug in the pancreatic islets, ${ }^{24}$ and persistent effects on B cell membranes. ${ }^{25}$

The diagnosis of hypoglycaemia should be considered in any patient treated with a sulphonylurea who has disturbed cerebral function. In elderly patients presenting with focal neurological signs hypoglycaemia can be confirmed by the neurological signs resolving when the blood glucose concentration has returned to normal. ${ }^{15}$

Severe hypoglycaemia requires hospital admission, and successful treatment depends on recognising that its course is often prolonged and that relapses are common. ${ }^{14} 152627 \mathrm{~A}$ bolus intravenous injection of $50 \%$ glucose should be given followed by an intravenous infusion of $10 \%$ or $20 \%$ glucose to keep the blood glucose concentration between 5 and 10 $\mathrm{mmol} / \mathrm{l}$. Blood glucose and potassium concentrations must be measured often until they are stable. Regular monitoring should continue for at least three days. If it proves impossible to maintain the glucose concentration in the required range adding hydrocortisone (100 mg every six hours) to the infusion may help. ${ }^{1528}$ Glucagon (1 mg every six hours) by intramuscular injection ${ }^{28}$ and the hypotensive agent diazoxide (75-100 mg every six hours) by continuous infusion may be useful. ${ }^{17} 2729$ It would be logical to use somatostatin or a longer acting analogue to prevent insulin release, and this has been successful in cases of hypoglycaemia induced by an insulinoma. ${ }^{30}$ The elimination of chlorpropamide, but not of other sulphonylureas, may be greatly enhanced by forced alkaline diuresis. ${ }^{31}$

Sulphonylurea induced hypoglycaemia would be less common if sulphonylureas were used only after dietary treatment had failed. Short acting drugs-for example, tolbutamide - should be prescribed routinely for susceptible individuals, particularly patients over 60.14-16 Treatment should be monitored with particular care in patients with impaired renal, cardiac, or hepatic function since hypoglycaemia in these patients often kills. Severe hypoglycaemia may occur in any patient treated with any sulphonylurea, and this potentially life threatening complication requires prolonged and energetic treatment.

R E FERNER

Senior Registrar,

Wolfson Unit of Clinical Pharmacology,

Royal Victoria Infirmary,

Newcastle upon Tyne NE1 4LP

H A W NEIL

Lecturer,

Department of Medicine,

University of Newcastle upon Tyne,

Newcastle upon Tyne NE2 4HH 
1 Clarke BF, Campbell IW. Long-term comparative trial of glibenclamide and chlorpropamide in diet-failed maturity-onset diabetes. Lancet 1974; i:246-8.

2 Dahlen M, Bergman U, Idman L, Martinsson L, Karlsson G. Epidemiology of hypoglycaemia in patients on oral antidiabetic drugs in the island of Gotland, Sweden. Acta Endocrinol (suppl) 1984;263:abst 21 .

3 Potter J, Clarke P, Gale AEM, Dave SH, Tattersall RB. Insulin-induced hypoglycaemia in an accident and emergency department: the tip of an iceberg? $\mathrm{Br} \mathrm{Med} \mathcal{F}$ 1982;285:1180-2.

Barnett AH, Leslie D, Watkins PJ. Can insulin-treated diabetics be given beta-adrenergic blocking drugs? BrMed f 1980;280:976-8.

5 Muhlhauser I, Berger M, Sonnenberg G, Koch J, Jorgens V, Schernthaner G, Scholz V. Incidence and management of severe hypoglycaemia in 434 adults with insulin-dependent diabetes mellitus. Diabetes Care 1985;8:268-73.

6 Casparie AF, Elving LD. Severe hypoglycaemia in diabetic patients: frequency, causes, prevention. Diabetes Care 1985;8:141-5.

7 Tunbridge WMG. Factors contributing to deaths of diabetics under fifty years of age. Lancet 1981;ii:569-72.

8 Neil HAW, Gatling G, Mather HM, et al. The Oxford Community Diabetes Study: evidence for an increase in the prevalence of known diabetes. Diabetic Medicine 1987;4:539-43.

9 Campbell IW. Metformin and glibenclamide: comparative risks. Br Med f 1984;289:289.

10 Berger W, Caduff F, Pasquel M, Rump A. Die relative Haufigkeit der schweren SulfonylharnstoffHypoglykamie in den letzten 25 Jahren in der Schweiz. Schweiz Med Wochenschr 1986;116: $145-51$.

11 Klimt CR, Knatterud GL, Meinert CL, Prout TE. The University Group Diabetes Program: study of the effects of hypoglycemic agents on vascular complications in patients with adultonset diabetes. II. Mortality results. Diabetes 1970;19(suppl 2):747-830.

12 Fuller JH. Clinical trials in diabetes mellitus. In: Mann J, Pylorala K, Teuscher A, eds. Diabetes in epidemiological perspective, Edinburgh: Churchill Livingstone, 1983:265-85

13 UK Prospective Study of Therapies of Maturity-Onset Diabetes. I. Effect of diet, sulphonylurea insulin or biguanide therapy on fasting plasma glucose and body weight over one year. Diabetologia 1983;24:404-11.

14 Asplund K, Wiholm B-E, Lithner F. Glibenclamide-associated hypoglycaemia: a report on 57 cases. Diabetologia 1983;24:412-7.

15 Selzer HS. Drug-induced hypoglycaemia: a review based on 473 cases. Diabetes 1972;21:955-66.
16 Sonnenblick M, Shilo S. Glibenclamide induced prolonged hypoglycaemia. Age Ageing 1986;15: $185-9$.

17 Johnson SF, Schade DS, Peake GT. Chlorpropamide-induced hypoglycaemia: successful treatment with diazoxide. Am F Med 1977;63:799-804

18 Ludman P, Mason P, Joplin GS. Dangerous misuse of sulphonylureas. $\mathrm{Br}$ Med $\mathcal{F}$ 1986;293: 1287-8.

19 Ferner RE, Chaplin S. Relationship between pharmacokinetics and pharmacodynamics of oral hypoglycaemic agents. Clin Pharmokinet 1987;12:379-401.

20 Frey HMM,. Rosenlund B. Studies in patients with chlorpropamide-induced hypoglycemia. Diabetes 1970;19:930-7.

21 Rogers HJ, Spector RG, Morrison PJ, Bradbrook ID. Pharmacokinetics of intravenous glibenclamide investigated by a high performance liquid chromatographic assay. Diabetologia 1982;23:37-40

22 Matsuda A, Kuzuya T, Sugita Y, Kawashima K. Plasma levels of glibenclamide in diabetic patients during routine clinical administration determined by a specific radioimmunoassay. Horm Metab Res 1983;15:425-8.

23 Axelgaard G, Skensved H, Asfeldt VH. Hypglykaemi ved behandling med sulfonylurinstoffer. Ugeskr Laeger 1986;8:2155-8.

24 Hellman B, Sehlin J, Taljedal I-B. Glibenclamide is exceptional among hypoglycaemic agents in accumulating progressively in B-cell rich pancreatic islets. Acta Endocrinol 1984;105: 385-90.

25 Matthews EK, Shotton PA. The control of ${ }^{80} \mathrm{Rb}$ efflux from rat isolated pancreatic islets by the sulphonylureas tolbutamide and glibenclamide. Br f Pharmacol 1984;82:689-700.

26 Gale EAM. Hypoglycaemia. Clin Endocrinol Metab 1980;9:461-75.

27 Marks V, Rose FC. Hypoglycaemia. 2nd ed. Oxford: Blackwell Scientific, 1981:368.

28 Davies DM, Macintyre A, Millar EJ, Bell SM, Mehra SK. Need for glucagon in severe hypoglycaemia induced by sulphonylurea drugs. Lancet 1967; ; $363-4$

29 Pfeifer MA, Wolter CF, Samols E. Management of chlorpropamide induced hypoglycaemia with diazoxide. South Med f 1978;71:606-8.

30 Verschoor L, Uitterlinden P, Lamberts SWJ, Del Pozo E. The use of a new somatostatin analogue in the treatment of hypoglycaemia in patients with insulinoma. Clin Endocrinol 1986;25:555-60.

31 Neuvonen PJ, Karkkainen S. The effects of charcoal, sodium bicarbonate, and ammonium chloride on chlorpropamide kinetics. Clin Pharmacol Ther 1983;33:386-93.

\section{Psychiatric illness among British Afro-Caribbeans}

Migrants often have higher rates of mental illness than the people among whom they settle. Hence not surprisingly West Indians in Britain have an above average admission rate to psychiatric hospitals ${ }^{1-3}$ but what is unexpected is that their rate for schizophrenia should be three to five times the white rate. ${ }^{1-6}$ The explanations offered include a selective pattern of migration ${ }^{4}$; the experience of migration and "status striving in a climate of limited opportunity" ${ }^{1-8}$; a culturally determined response to adversity ${ }^{9}$; and patterns of service utilisation..$^{267}$ The question of diagnostic accuracy has also been raised ${ }^{145}$ : acute psychotic reactions, which are common as shortlived responses to stress in developing countries, may be diagnosed in Britain as schizophrenia. ${ }^{510} 11$ The misdiagnosis hypothesis may be supported by the fact that depression is less commonly diagnosed among West Indians, ${ }^{37}$ and Cochrane and Bal have recently examined the various hypotheses for the high rates of schizophrenia among British Afro-Caribbeans and emphasised misdiagnosis. ${ }^{11}$

Hospital admission figures may be misleading because patients' birthplaces are sometimes not recorded. ${ }^{12}$ Remarkably there is only one study of minor psychiatric disorder outside hospital, and it found higher rates of depression and psychosomatic illness among Afro-Caribbeans than among whites. ${ }^{13}$ It appears that depressed West Indians seldom seek psychiatric treatment, are seldom offered admission, and if they are admitted they are likely to be diagnosed as schizophrenic. Suicide among Afro-Caribbeans is less common than among whites, while overdoses are equally common in those over 25, but lower among those under $25 .{ }^{214}$ Whether Afro-Caribbeans actually do have lower rates of minor psychiatric problems (which seems unlikely), the psychiatric perception of their illnesses is that they are more somatic: West Indians are seldom offered psychotherapy and are more likely to be given electroconvulsive therapy and higher doses of medication. ${ }^{15}$

Another troubling aspect of service delivery to AfroCaribbeans is the high admission rate under the Mental
Health Act and the overrepresentation of black patients in secure units and special hospitals. ${ }^{16}$ Doctors explain these figures by saying that illness among black patients is more antisocial or that stigmatisation of mental illness by West Indians leads to a poor relationship between them and psychiatry. ${ }^{17}$ There is no evidence for either of these explanations. We know little about stigmatisation of mental illness in any minority group (or, indeed, among the white population). By contrast, a now justifiably alarmed black community argues that racism in psychiatry is highlighted by the frequency of the controversial diagnosis of "cannabis psychosis," which in some psychiatric hospitals is given to over a quarter of Afro-Caribbean men ${ }^{18}$ (R Littlewood, unpublished observations). Black Britons have responded by establishing psychiatric aftercare facilities for black patients.

Children of immigrants usually have a similar rate of psychiatric illness to the population among which their parents have settled, but disturbingly this is not so in Britain for the children of West Indian immigrants. Two recent studies suggest that their first admission rates for schizophrenia are even higher than those of their parents. McGovern and Cope found that the figure for British born Afro-Caribbean men was seven times the white rate, and for women it was 13 times higher..$^{18}$ In a prospective study Harrison and others found a mean annual incidence rate 16 times higher for British born Afro-Caribbeans aged 16-29 than for British born whites. ${ }^{19}$ Both papers reject explanations in terms of genetics or "West Indian culture." Could misdiagnosis be responsible? Harrison and his colleagues, using the present state examination, found a similar excess at all degrees of a "certainty of schizophrenia" coding. We think that an important aetiological factor is the precipitation of schizophrenia in those vulnerable by the experience of racism refracted through subtle cognitive changes, including selfhood, autonomy, and locus of control.

Because British born blacks are mostly young we have only recently been able to look at adult mental illness. The 